ARTICLE

Received 28 Apr 2016 | Accepted 7 Dec 2016 | Published 6 Mar 2017

DOI: $10.1038 /$ ncomms14264

OPEN

\title{
Low-crystalline iron oxide hydroxide nanoparticle anode for high-performance supercapacitors
}

Kwadwo Asare Owusu ${ }^{1, \star}$, Longbing $\mathrm{Qu}^{1,2, \star}$, Jiantao $\mathrm{Li}^{1}$, Zhaoyang Wang ${ }^{1}$, Kangning Zhao ${ }^{1}$, Chao Yang ${ }^{1}$, Kalele Mulonda Hercule ${ }^{3}$, Chao Lin ${ }^{1}$, Changwei Shi ${ }^{1}$, Qiulong Wei ${ }^{1}$, Liang Zhou ${ }^{1} \&$ Liqiang Mai ${ }^{1}$

Carbon materials are generally preferred as anodes in supercapacitors; however, their low capacitance limits the attained energy density of supercapacitor devices with aqueous electrolytes. Here, we report a low-crystalline iron oxide hydroxide nanoparticle anode with comprehensive electrochemical performance at a wide potential window. The iron oxide hydroxide nanoparticles present capacitances of 1,066 and $716 \mathrm{Fg}^{-1}$ at mass loadings of 1.6 and $9.1 \mathrm{mg} \mathrm{cm}^{-2}$, respectively, a rate capability with $74.6 \%$ of capacitance retention at $30 \mathrm{Ag}^{-1}$, and cycling stability retaining $91 \%$ of capacitance after 10,000 cycles. The performance is attributed to a dominant capacitive charge-storage mechanism. An aqueous hybrid supercapacitor based on the iron oxide hydroxide anode shows stability during float voltage test for $450 \mathrm{~h}$ and an energy density of $104 \mathrm{Wh} \mathrm{kg}^{-1}$ at a power density of $1.27 \mathrm{~kW} \mathrm{~kg}^{-1}$. A packaged device delivers gravimetric and volumetric energy densities of 33.14 $\mathrm{Wh} \mathrm{kg}^{-1}$ and $17.24 \mathrm{WhI}^{-1}$, respectively.

\footnotetext{
${ }^{1}$ State Key Laboratory of Advanced Technology for Materials Synthesis and Processing, International School of Materials Science and Engineering, Wuhan University of Technology, Wuhan 430070, China. ${ }^{2}$ Department of Mechanical and Aerospace Engineering, Monash University, Melbourne, VIC 3800 , Australia. ${ }^{3}$ Department of Chemistry, University of Kinshasa, No. 1 University Street, BP. Kinshasa IX, Democratic Republic of the Congo. * These authors contributed equally to this work. Correspondence and requests for materials should be addressed to L.Z. (email: liangzhou@whut.edu.cn) or to L.M. (email: mlq518@whut.edu.cn).
} 
D ue to the fast depletion of fossil fuels and global warming, there is an urgent need for clean energy technologies to supplement and replace the conventional energy sources. At the forefront of clean energy technologies are highperformance energy storage devices, which are needed for the next-generation consumer electronics, biomedical devices and hybrid electric vehicles ${ }^{1-3}$. As a well-known energy storage device, the supercapacitor has attracted tremendous research attention recently due to its high power density $\left(1-10 \mathrm{~kW} \mathrm{~kg}^{-1}\right)$, fast charge and discharge rate (within seconds) and long cycling life $(>100,000 \text { cycles })^{4-7}$. Electrical double-layer capacitor (EDLC) materials have been widely used in supercapacitors due to their large specific surface area, high electrical conductivity and low cost ${ }^{8-11}$. Although high power density and cycling stability have been realized by these materials, the attained capacitance and energy density are typically low ${ }^{12-14}$. This is because of the charge-storage mechanism for EDLC materials, which is dominated by charge separation at the electrode/electrolyte interface ${ }^{14,15}$. Pseudocapacitor materials can provide a higher capacitance than EDLC materials due to their surface/ near-surface redox reactions ${ }^{1,4,16-18}$.

Currently, the research on supercapacitor is focused on increasing the energy density while retaining comparable high power density ${ }^{19}$. Asymmetric and hybrid supercapacitors (HSCs) have been extensively studied as a promising strategy to increase the energy density ${ }^{20-26}$. A typical HSC consists of both faradaic and capacitive electrodes ${ }^{12,27}$. This design results in high energy density due to the contributions from the different charge-storage mechanisms and the extended operating potential window in aqueous electroytes (up to $2 \mathrm{~V})^{28,29}$. Faradaic cathode materials have been extensively studied leading to the development of highperformance cathodes for aqueous supercapacitors $20,21,30-32$. For instance, nickel-based oxides have been explored due to their improved electronic conductivity and rich redox reactions, arising from the high electrochemical activity of $\mathrm{Ni}^{26,28,33,34}$. Despite the high performance of these cathode materials, the maximum energy density of their hybrid cells in aqueous electrolytes is largely hindered by the low specific capacitance of commonly used carbon anodes ${ }^{35-37}$. Recently, crystalline iron oxides $\left(\mathrm{Fe}_{2} \mathrm{O}_{3}\right.$, $\left.\mathrm{Fe}_{3} \mathrm{O}_{4}\right)$ and iron oxide hydroxide $(\mathrm{FeOOH})$ have been studied as supercapacitor or battery-type anode materials due to their high theoretical capacitance, wide operating potential window, low cost and natural abundance ${ }^{38-44}$. Even though significant progress has been achieved for these materials, most of them exhibit short cycle life and poor rate performance. Low-crystalline or amorphous metal oxides are capable of achieving better cycling stability than the high-crystalline counterpart because of their more structural defects and disorder ${ }^{30,45-47}$. As far as we know, it is still a tremendous challenge to obtain anode materials with high capacitance, good rate capability and excellent cycling stability.

In the present work, we report a capacitive dominant $\mathrm{FeOOH}$ nanoparticle anode with comprehensive electrochemical performance at a wide potential window. The synthesis of the $\mathrm{FeOOH}$ nanoparticle anode involves the hydrothermal growth of iron oxide $\left(\alpha-\mathrm{Fe}_{2} \mathrm{O}_{3}\right)$ nanoparticles on carbon fibre cloth (CFC) and the subsequent electrochemical transformation to low-crystalline $\mathrm{FeOOH}$ nanoparticles. The $\mathrm{FeOOH}$ anode manifests high specific capacitances at both low and high mass loadings, good rate capability $\left(74.6 \%\right.$ capacitance retention at $\left.30 \mathrm{Ag}^{-1}\right)$ and excellent cycling stability (91\% capacitance retention after 10,000 cycles). To further evaluate the performance of the $\mathrm{FeOOH}$ nanoparticle anode for aqueous HSCs, we also designed the suitable battery-type cathode, nickel molybdate $\left(\mathrm{NiMoO}_{4}\right)$ using a hydrothermal method. An $\mathrm{NiMoO}_{4} / / \mathrm{FeOOH}$ aqueous hybrid device displays high specific capacitance $\left(273 \mathrm{Fg}^{-1}\right)$, high energy density (104.3 $\mathrm{Wh} \mathrm{kg}^{-1}$ ) and exceptional stability. Importantly, a packaged device with an active material weight percentage of $35 \%$ shows high gravimetric and volumetric energy densities.

\section{Results}

Synthesis and characterization of $\alpha-\mathrm{Fe}_{2} \mathrm{O}_{3}$ nanoparticles. We first synthesized $\mathrm{Fe}_{2} \mathrm{O}_{3}$ nanoparticles on $\mathrm{CFC}$ substrate through a facile hydrothermal method (Supplementary Fig. 1). Fig. 1a shows the X-ray diffraction (XRD) pattern of the $\mathrm{Fe}_{2} \mathrm{O}_{3}$. The XRD pattern can be indexed to rhombohedral $\alpha-\mathrm{Fe}_{2} \mathrm{O}_{3}$ (JCPDS card no. 00-033-0664) with R-3c space group and lattice parameters of $a=b=5.0356 \AA$ and $c=13.7500 \AA$. The $\alpha-\mathrm{Fe}_{2} \mathrm{O}_{3}$ sample was further characterized by Raman spectroscopy (Fig. 1b). A distant band is located at $1,316 \mathrm{~cm}^{-1}$ and the narrow bands located at 221 and $492 \mathrm{~cm}^{-1}$ can be assigned to the $A_{1 \mathrm{~g}}$ modes, while the bands located at 247,291, 407 and $607 \mathrm{~cm}^{-1}$ are due to the $\mathrm{E}_{1 \mathrm{~g}}$ modes of $\alpha-\mathrm{Fe}_{2} \mathrm{O}_{3}{ }^{48,49}$. The Raman spectrum confirms the existence of $\alpha-\mathrm{Fe}_{2} \mathrm{O}_{3}$. The surface area of the $\alpha-\mathrm{Fe}_{2} \mathrm{O}_{3}$ was also studied by nitrogen sorption (Supplementary Fig. 2a). The Brunauer-Emmett-Teller (BET) surface area of the $\alpha$ $\mathrm{Fe}_{2} \mathrm{O}_{3}$ is determined to be $41 \mathrm{~m}^{2} \mathrm{~g}^{-1}$.

The morphology of $\alpha-\mathrm{Fe}_{2} \mathrm{O}_{3}$ was identified with scanning electron microscopy (SEM) and transmission electron microscopy (TEM). As shown in Fig. 1c, uniformly distributed nanoparticle morphology can be observed. The SEM image at a higher magnification (Fig. 1c, inset) reveals that the nanoparticles are uniform in size and strongly attached to the CFC substrate. From the TEM image (Fig. 1d), the diameter of the nanoparticles is determined to be $\sim 30 \mathrm{~nm}$. The high-resolution TEM (HRTEM) image of the $\alpha-\mathrm{Fe}_{2} \mathrm{O}_{3}$ nanoparticles is shown in Fig. 1e. Lattice fringes with interplanar spacing of $0.36 \mathrm{~nm}$ corresponding to the $\left(\begin{array}{lll}0 & 1 & 2\end{array}\right)$ plane of $\alpha-\mathrm{Fe}_{2} \mathrm{O}_{3}$ can be clearly discerned. The polycrystalline feature of the $\alpha-\mathrm{Fe}_{2} \mathrm{O}_{3}$ nanoparticles is confirmed by the selected area electron diffraction (SAED) pattern (Fig. 1f). It shows a set of concentric rings, which can be indexed to the (104), (113), (116) and (300) diffractions of rhombohedral $\alpha-\mathrm{Fe}_{2} \mathrm{O}_{3}$.

Transformation into low-crystalline $\mathrm{FeOOH}$ nanoparticles. The $\alpha-\mathrm{Fe}_{2} \mathrm{O}_{3}$ is transformed into low-crystalline $\mathrm{FeOOH}$ during electrochemical cycles in the potential range between -1.2 and $0 \mathrm{~V}$ versus saturated calomel electrode (SCE) (Supplementary Fig. 1). The cyclic voltammetry (CV) curves of the $\alpha-\mathrm{Fe}_{2} \mathrm{O}_{3}$ electrode at different cycles in $2 \mathrm{M} \mathrm{KOH}$ are shown in Fig. 2a. A pair of faradaic peaks positioned at -0.66 and $-1.05 \mathrm{~V}$ versus SCE is observed during the first cycle. The intensity of the peaks gradually reduces during the first ten cycles (defined as activation process) and becomes stable afterwards, which suggests that some changes in crystalline structure have occurred during the first ten cycles. The $\mathrm{CV}$ curves after the activation process portray a quasirectangular shape with very broad peaks. To understand the structure changes and charge-storage mechanism of the anode, ex situ XRD, X-ray photoelectron spectroscopy (XPS), SEM and TEM tests were carried out. As shown in Fig. $2 b$, the $\alpha-\mathrm{Fe}_{2} \mathrm{O}_{3}$ is transformed into $\mathrm{FeOOH}$ (JCPDS No. 01-077-0247) after ten electrochemical cycles. The $\alpha-\mathrm{Fe}_{2} \mathrm{O}_{3}$ phase cannot be recovered in the subsequent discharge process, instead, a mixture of $\mathrm{FeOOH}$ and $\mathrm{Fe}(\mathrm{OH})_{2}$ is obtained. SEM images of the transformed $\mathrm{FeOOH}$ show that the nanoparticle morphology is well maintained (Supplementary Fig. 3). Also, the TEM and HRTEM images (Fig. 2c,d) further confirm that the $\alpha-\mathrm{Fe}_{2} \mathrm{O}_{3}$ is transformed into low-crystalline $\mathrm{FeOOH}$ nanoparticles during the activation process. XPS test was carried out to confirm the valence states of the various elements on the surface of $\alpha-\mathrm{Fe}_{2} \mathrm{O}_{3}$ after activation. The Fe $2 p$ core-level spectrum (Fig. 2 e) shows two characteristic 

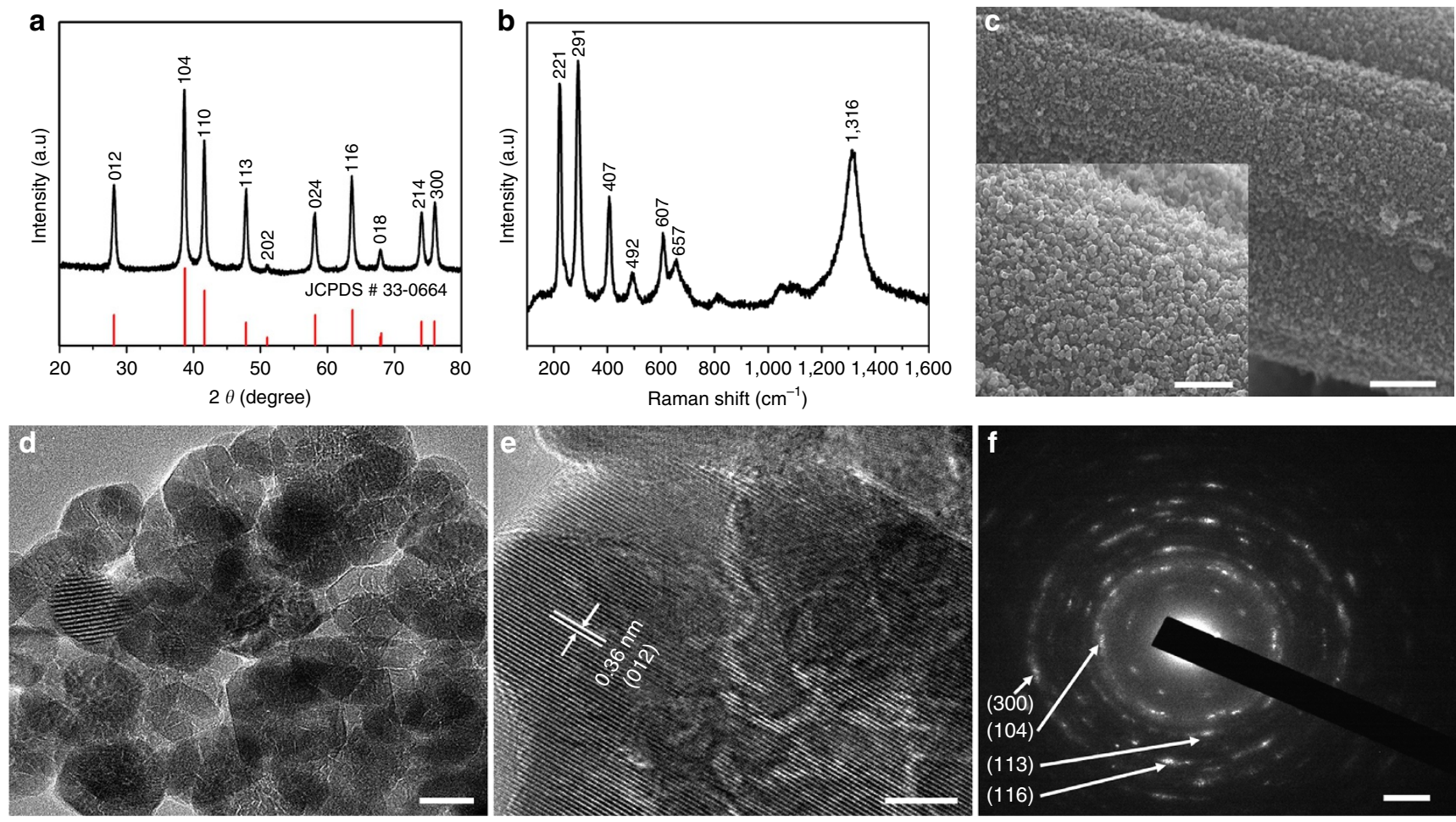

Figure 1 | Material characterization of $\boldsymbol{\alpha}-\mathbf{F e}_{\mathbf{2}} \mathbf{O}_{\mathbf{3}}$ nanoparticles. (a) XRD pattern. (b) Raman spectrum. (c) SEM images. Scale bars, $1 \mu \mathrm{m}$ (inset: $500 \mathrm{~nm}$ ). (d) TEM image. Scale bar, $20 \mathrm{~nm}$. (e) HRTEM image. Scale bar, $5 \mathrm{~nm}$. (f) SAED pattern. Scale bar, $2 \mathrm{~nm}^{-1}$.

peaks located at 711 and $725 \mathrm{eV}$ corresponding to $\mathrm{Fe} 2 p_{1 / 2}$ and $\mathrm{Fe}$ $2 p_{3 / 2}$ spin orbitals of $\mathrm{FeOOH}$, together with two satellite peaks at 717 and $733 \mathrm{eV}^{46,47}$. The deconvolution of the $\mathrm{O} 1 \mathrm{~s}$ core-level spectrum (Fig. 2f) shows three distinct oxygen contributions corresponding to $\mathrm{H}-\mathrm{O}-\mathrm{H}(532.7 \mathrm{eV})$, $\mathrm{Fe}-\mathrm{O}-\mathrm{H}(531.4 \mathrm{eV})$ and Fe-O-Fe bonds $(530.4 \mathrm{eV})^{46,47,50}$. The H-O-H bond corresponds to water molecule, which suggests that the $\mathrm{FeOOH}$ nanoparticles are in hydrated form $^{50}$. The XPS characterization confirms the electrochemical transformation of $\alpha-\mathrm{Fe}_{2} \mathrm{O}_{3}$ nanoparticles to $\mathrm{FeOOH}$ nanoparticles, which is highly consistent with the ex situ XRD, SEM and TEM results. According to the above characterizations, the probable transformation reaction and charge-storage mechanism is proposed as follows:

The activation process : $\mathrm{Fe}_{2} \mathrm{O}_{3}+\mathrm{H}_{2} \mathrm{O} \rightarrow 2 \mathrm{FeOOH}$

$$
\begin{aligned}
& \text { Subsequent discharge process : } \mathrm{FeOOH}+\mathrm{H}_{2} \mathrm{O}+\mathrm{e}^{-} \\
& \quad \rightarrow \mathrm{Fe}(\mathrm{OH})_{2}+\mathrm{OH}^{-}
\end{aligned}
$$

$$
\begin{aligned}
& \text { Subsequent charge process : } \mathrm{Fe}(\mathrm{OH})_{2}+\mathrm{OH}^{-} \\
& \rightarrow \mathrm{FeOOH}+\mathrm{H}_{2} \mathrm{O}+\mathrm{e}^{-}
\end{aligned}
$$

Electrochemical performance of $\mathrm{FeOOH}$ nanoparticles. To study the electrochemical performance of the low-crystalline $\mathrm{FeOOH}$ nanoparticles, $\mathrm{CV}$ and galvanostatic charge/discharge tests were carried out in a three-electrode system with a Pt plate counter-electrode and an SCE reference electrode in $2 \mathrm{M} \mathrm{KOH}$ electrolyte. Fig. 3a displays the $\mathrm{CV}$ curves of the $\mathrm{FeOOH}$ nanoparticles tested at different scan rates ranging from 5 to $50 \mathrm{mV} \mathrm{s}^{-1}$ in a -1.2 to $0 \mathrm{~V}$ versus SCE potential window. The quasirectangular shape $\mathrm{CV}$ curves of the $\mathrm{FeOOH}$ nanoparticle anode denote an electrochemical signature of a typical pseudocapacitive electrode ${ }^{12,27}$. The symmetric CV curves also indicate that the charge storage process and the redox reactions are reversible. The charge/discharge curves of the $\mathrm{FeOOH}$ nanoparticles are shown in Supplementary Fig. 4a. The specific gravimetric and areal capacitances of the $\mathrm{FeOOH}$ nanoparticles are calculated from the discharge curves. As displayed in Fig. 3b and Supplementary Fig. $4 \mathrm{~b}$, the $\mathrm{FeOOH}$ nanoparticles exhibit a capacitance of $1,066 \mathrm{~F} \mathrm{~g}^{-1}\left(1.71 \mathrm{~F} \mathrm{~cm}^{-2}\right)$ at $1 \mathrm{Ag}^{-1}$. With the increase of the current density to $30 \mathrm{Ag}^{-1}$, a capacitance of $796 \mathrm{~F} \mathrm{~g}^{-1}\left(1.27 \mathrm{~F} \mathrm{~cm}^{-2}\right)$ can be maintained, corresponding to $74.6 \%$ of the capacitance at $1 \mathrm{Ag}^{-1}$. Another important performance metric in characterizing supercapacitor electrodes is the mass loading of the active materials ${ }^{51}$. Considering the mass loading of typical industrial porous carbon electrodes $\left(\sim 10 \mathrm{mg} \mathrm{cm}^{-2}\right)$, we tuned the mass loading of the $\mathrm{FeOOH}$ anode. The $\mathrm{FeOOH}$ anode displays quasirectangular-shaped $\mathrm{CV}$ curves and symmetric triangular charge/discharge curves irrespective of the mass loading (Supplementary Fig. 5). With mass loadings of $1.6,3.0,5.6$ and $9.1 \mathrm{mg} \mathrm{cm}^{-2}$, the low-crystalline $\mathrm{FeOOH}$ nanoparticle anode displays specific gravimetric capacitances of $1,066,996,827$ and $716 \mathrm{Fg}^{-1}$ at $1 \mathrm{Ag}^{-1}$, respectively (Fig. 3c). The capacitances of the FeOOH anode decrease with increasing mass loadings; however, they still exhibit good rate capabilities (Supplementary Fig. 6b). The areal and volumetric capacitances of the $\mathrm{FeOOH}$ anode (including the volume of the current collector) with a high mass loading of $9.1 \mathrm{mg} \mathrm{cm}^{-2} \mathrm{can}$ reach as high as $6.5 \mathrm{~F} \mathrm{~cm}^{-2}$ (Fig. 3c) and $186 \mathrm{~F} \mathrm{~cm}^{-3}$ (Fig. 3d).

As one of the main parameters for supercapacitors, the longterm cycling stability of the $\mathrm{FeOOH}$ anode was studied (Fig. 3e). For the $\mathrm{FeOOH}$ anode with a mass loading of $1.6 \mathrm{mg} \mathrm{cm}^{-2}$, $91 \%$ of the initial capacitance can be retained after 10,000 charge/discharge cycles at $30 \mathrm{Ag}^{-1}$, whereas $86 \%$ of the initial capacitance is retained for the anode with a mass loading of $9.1 \mathrm{mg} \mathrm{cm}^{-2}$ after 10,000 cycles at $15 \mathrm{Ag}^{-1}$. At $1 \mathrm{Ag}^{-1}$, the $\mathrm{FeOOH}$ electrode displays a low voltage drop of $0.0097 \mathrm{~V}$, suggesting a low internal resistance $\left(R_{\mathrm{s}}\right)$ of the electrode 

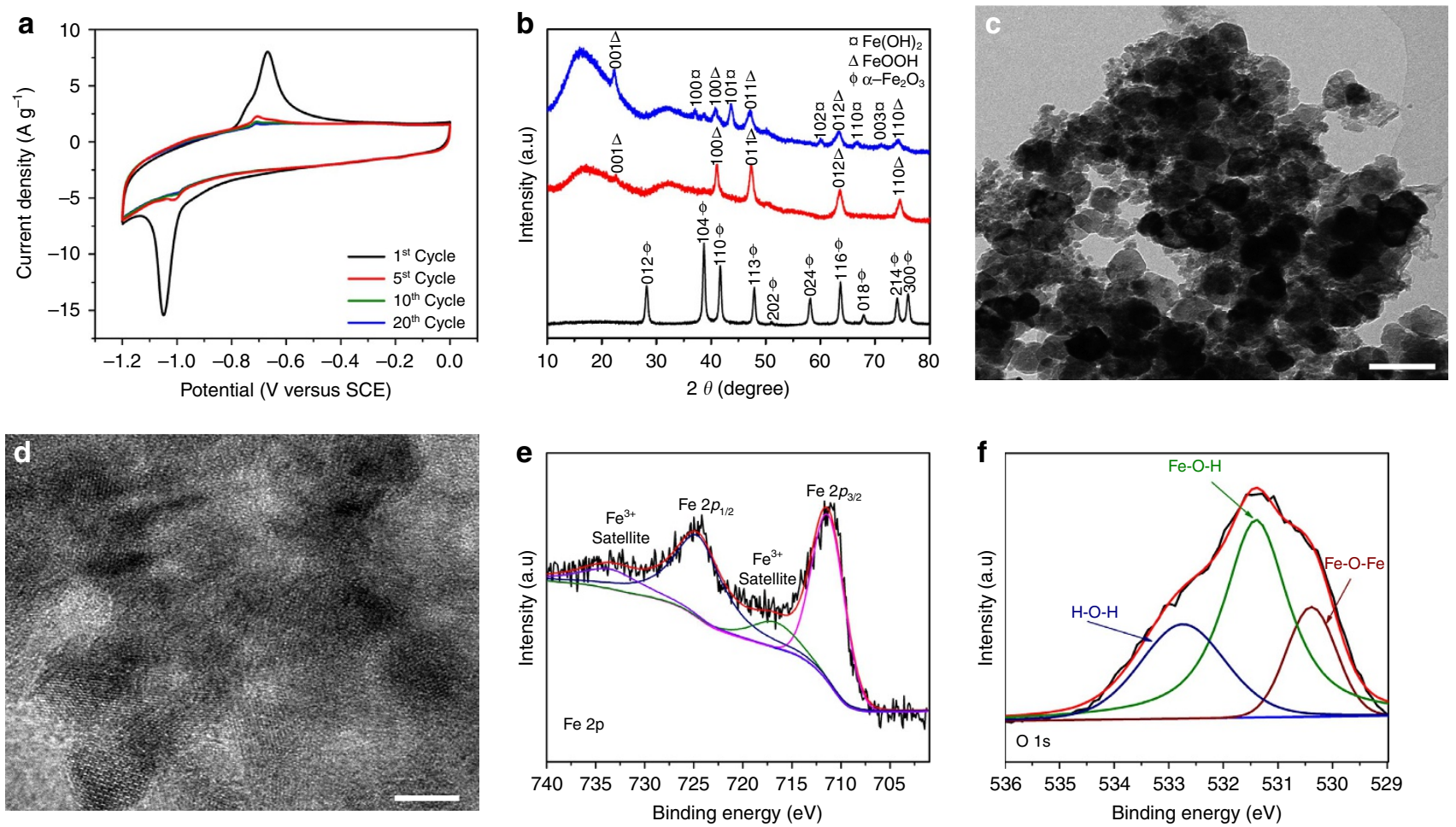

Figure 2 | Transformation of $\alpha-\mathrm{Fe}_{\mathbf{2}} \mathbf{O}_{\mathbf{3}}$ into FeOOH nanoparticles. (a) CV curves of $\alpha-\mathrm{Fe}_{2} \mathrm{O}_{3}$ electrode at $2 \mathrm{mVs}{ }^{-1}$. (b) XRD patterns of the electrodes before activation (black line), after activation in charge state (red line), and after activation in discharge state (blue line). (c) TEM image of FeOOH nanoparticles. Scale bar, $100 \mathrm{~nm}$. (d) HRTEM images of FeOOH nanoparticles. Scale bar, $5 \mathrm{~nm}$. (e,f) Fe2p and O 1s XPS core-level spectra of FeOOH nanoparticles.
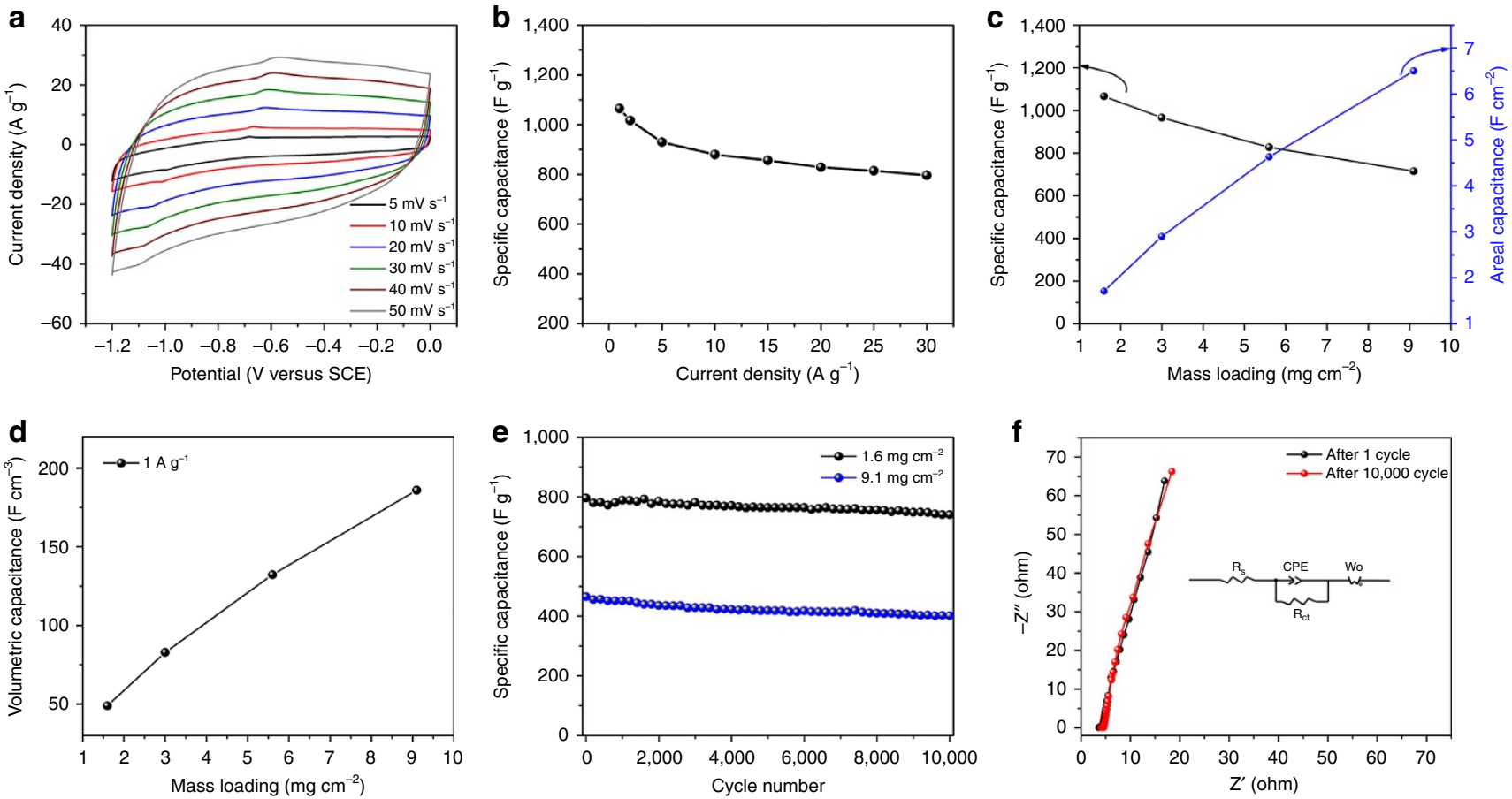

Figure 3 | Electrochemical performance of FeOOH nanoparticle anode. (a) CV curves. (b) Specific gravimetric capacitance as a function of current density. (c) Specific gravimetric and areal capacitances of the FeOOH nanoparticle anode at different mass loadings. (d) Volumetric capacitance of the $\mathrm{FeOOH}$ nanoparticle anode (including the volume of the current collectors) at different mass loadings. (e) $\mathrm{Cycling}$ performance of the FeOOH nanoparticle anode at 1.6 and $9.1 \mathrm{mg} \mathrm{cm}^{-2}$. (f) Nyquist plot after 1st and 10,000th cycle.

$(3.45 \Omega)^{52}$. The $R_{\mathrm{s}}$ and charge transfer resistance $\left(R_{\mathrm{ct}}\right)$ after the first cycle obtained from the simulation of the Nyquist plot are 3.59 and $0.59 \Omega$, respectively (Fig. 3f). After 10,000 charge/ discharge cycles, the $R_{\mathrm{s}}$ increases to $4.10 \Omega$, whereas the $R_{\mathrm{ct}}$ reduces to $0.50 \Omega$ (Supplementary Table 1). The reduced $R_{\mathrm{ct}}$ suggests that the low-crystalline $\mathrm{FeOOH}$ facilitates fast 
diffusion of electrolyte ions, advantageous to the long-term stability of the anode ${ }^{53}$.

Synthesis and characterization of $\mathrm{NiMoO}_{4}$ nanowires. The synthesis of $\mathrm{NiMoO}_{4}$ nanowire cathode was achieved through a hydrothermal method followed by postannealing. The crystallographic phase of $\mathrm{NiMoO}_{4}$ was characterized by XRD analysis. Fig. 4a depicts the Rietveld refined XRD pattern of the $\mathrm{NiMoO}_{4}$. The lattice parameters of $\mathrm{NiMoO}_{4}(a=9.5982 \AA$, $b=8.7760 \AA$ and $c=7.6717 \AA$ ) calculated by Rietveld refinement match well with monoclinic $\mathrm{NiMoO}_{4}$ (JCPDS No. 01-086-0361; $a=9.5660 \AA, b=8.7340 \AA$ and $c=7.6490 \AA)$. The weighted profile Rietveld factor $\left(R_{\mathrm{wp}}\right)$ of the $\mathrm{NiMoO}_{4}$ is determined to be $6.853 \%$ (Supplementary Table 2). XPS was applied to verify the surface composition of the $\mathrm{NiMoO}_{4}$ nanowires (Supplementary Fig. 7a). The Ni $2 p$ core-level spectrum shows two major peaks with binding energies of 856.19 and $873.92 \mathrm{eV}$, corresponding to $\mathrm{Ni} 2 p_{1 / 2}$ and $\mathrm{Ni} 2 p_{3 / 2}$ of $\mathrm{Ni}^{2+}$, respectively (Supplementary Fig. $7 \mathrm{~b})^{54,55}$. The Mo $3 d$ core-level spectrum presents two characteristic peaks with binding energies of 232.36 and $235.5 \mathrm{eV}$, corresponding to Mo $3 d_{5 / 2}$ and Mo $3 d_{3 / 2}$ of $\mathrm{Mo}^{6+}$, respectively (Supplementary Fig. $\left.7 \mathrm{c}\right)^{56,57}$. Last, the deconvolution of $\mathrm{O} 1 \mathrm{~s}$ core-level spectrum shows two major oxygen contributions (Supplementary Fig. 7d). The peak located at $530.4 \mathrm{eV}$ is associated with the metal-oxygen bond, while the peak at $531.4 \mathrm{eV}$ corresponds to the lattice oxygen $^{57}$.

The morphology of $\mathrm{NiMoO}_{4}$ grown on nickel foam substrate was observed with SEM and TEM. From the low-magnification SEM (Fig. $4 \mathrm{~b}$ and inset), it can be easily observed that the nanowires are grown on the surface of the nickel foam. A highmagnification SEM (Fig. 4c) shows that the bundled nanowires have needle-like tips. The presence of spaces between adjacent nanowires would enhance the penetration of the electrolyte ions ${ }^{28,58}$. TEM image of a typical $\mathrm{NiMoO}_{4}$ nanowire is shown in
Fig. $4 \mathrm{~d}$. The diameter of the $\mathrm{NiMoO}_{4}$ nanowires is determined to be $50-100 \mathrm{~nm}$. The HRTEM image of the $\mathrm{NiMoO}_{4}$ nanowire is

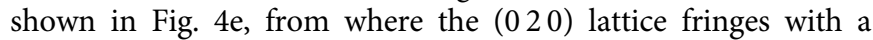
lattice spacing of $0.43 \mathrm{~nm}$ is clearly observed. The polycrystallinity of the $\mathrm{NiMoO}_{4}$ nanowires is confirmed from the SAED pattern (Fig. 4f), as it shows Bragg spots corresponding well with (-205), (2 04$),(-113),(111)$ and (-313) planes of monoclinic $\mathrm{NiMoO}_{4}$. The $\mathrm{NiMoO}_{4}$ displays a type II isotherm with an $\mathrm{H} 3$ hysteresis loop (Supplementary Fig. 2b), and the BET surface area is determined to be $49 \mathrm{~m}^{2} \mathrm{~g}^{-1}$.

Electrochemical performance of $\mathrm{NiMoO}_{4}$ nanowires. Fig. $5 \mathrm{a}$ shows the CV curves of $\mathrm{NiMoO}_{4}$ at different scan rates from 1 to $10 \mathrm{mV} \mathrm{s}^{-1}$ tested between 0 and $0.5 \mathrm{~V}$ versus SCE. From the linear sweep voltammetry (LSV) analysis (Supplementary Fig. 8f), it can be observed that oxygen evolution starts at $\sim 0.52 \mathrm{~V}$ versus SCE in the $\mathrm{NiMoO}_{4}$ electrode. Thus, it is safe for $\mathrm{NiMoO}_{4}$ to be cycled between 0 and $0.5 \mathrm{~V}$ versus SCE. The charge-storage mechanism in $\mathrm{NiMoO}_{4}$ can be ascribed to faradaic battery-type mechanism from the sharp peaks of the CV curves ${ }^{12,27}$. The curves show a pair of anodic and cathodic peaks arising from the fast faradaic redox reactions of $\mathrm{Ni}(\mathrm{II}) \leftrightarrow \mathrm{Ni}$ (III) during charge and discharge $28,55,56$. The $\mathrm{NiMoO}_{4}$ nanowires exhibit very good electrochemical reversibility as evidenced by the near mirror symmetry of both anodic and cathodic peaks ${ }^{55}$. The specific capacity instead of specific capacitance of the $\mathrm{NiMoO}_{4}$ cathode was calculated from the discharge curves (Supplementary Fig. 9a) to give realistic values of the energy storage and release ${ }^{12,27,36}$ As shown in Fig. 5b and Supplementary Fig. 9b, the $\mathrm{NiMoO}_{4}$ electrode delivers a specific capacity of $223 \mathrm{mAhg}^{-1}$ $\left(0.33 \mathrm{mAh} \mathrm{cm}^{-2}\right)$ at $1 \mathrm{Ag}^{-1}$ and $59 \%$ of the capacity can be retained at $30 \mathrm{Ag}^{-1}\left(130 \mathrm{mAh} \mathrm{g}^{-1}, 0.2 \mathrm{mAh} \mathrm{cm}^{-2}\right)$. The longterm cycling performance of the $\mathrm{NiMoO}_{4}$ nanowires was also studied. The $\mathrm{NiMoO}_{4}$ nanowires display capacitance retention of $85.1 \%$ after 10,000 charge/discharge cycles at $30 \mathrm{Ag}^{-1}$ (Fig. 5c).
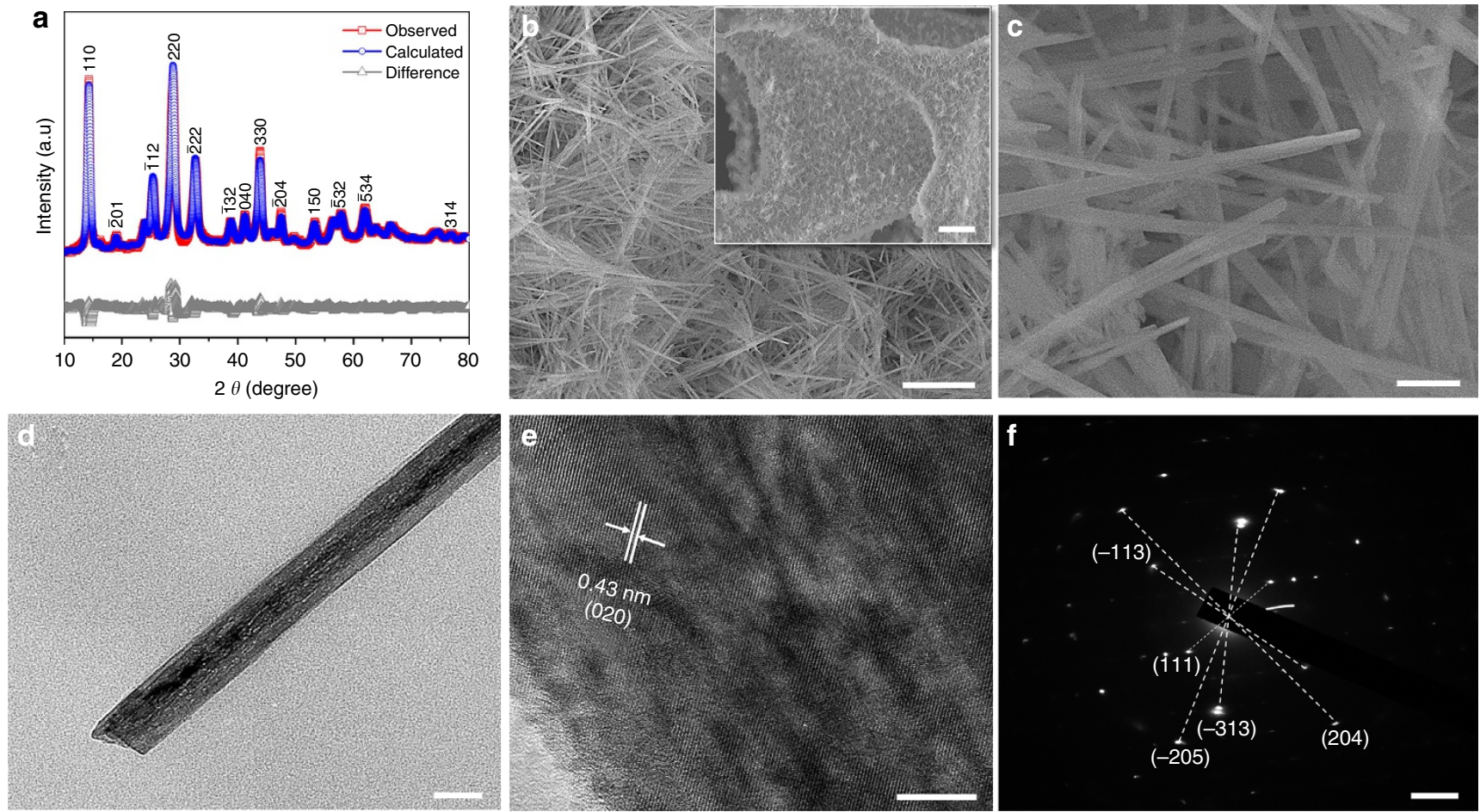

Figure 4 | Material characterization of $\mathbf{N i M o O}_{\mathbf{4}}$ nanowires. (a) Rietveld refined XRD pattern. (b) Low magnification SEM images. Scale bar, $3 \mu \mathrm{m}$ (inset $30 \mu \mathrm{m}$ ). (c) High magnification SEM image. Scale bar, $300 \mathrm{~nm}$. (d) TEM image. Scale bar, $50 \mathrm{~nm}$. (e) HRTEM image. Scale bar, $10 \mathrm{~nm}$. (f) SAED pattern. Scale bar, $2 \mathrm{~nm}^{-1}$. 

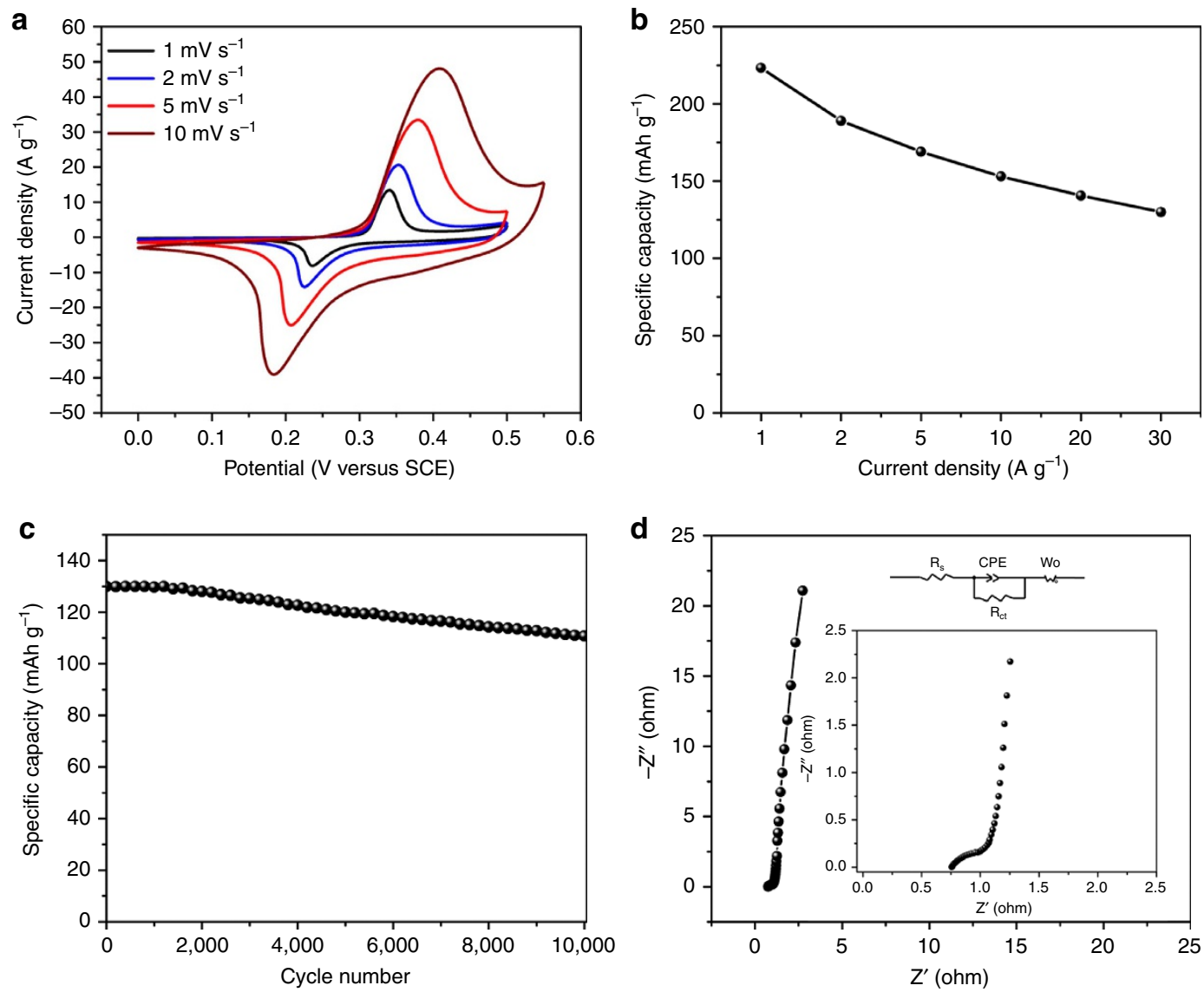

Figure 5 | Electrochemical performance of the $\mathrm{NiMoO}_{\mathbf{4}}$ nanowire cathode. (a) CV curves. (b) Specific capacity as a function of current density. (c) Cycling performance at $30 \mathrm{Ag}^{-1}$. (d) Nyquist plot, inset is the magnified view of the Nyquist plot in high-frequency region.

To provide further insights, EIS was measured to quantify the resistance at the electrode/electrolyte interface (Fig. 5d). The $\mathrm{NiMoO}_{4}$ nanowires display $R_{\mathrm{s}}$ and $R_{\mathrm{ct}}$ values of 0.72 and $0.15 \Omega$, respectively.

Electrochemical evaluation of aqueous HSC. To further evaluate the practical application of the $\mathrm{FeOOH}$ anode, an aqueous HSC was assembled with the $\mathrm{NiMoO}_{4}$ and $\mathrm{FeOOH}$ as the cathode and anode, respectively. The $\mathrm{NiMoO}_{4}$ cathode and $\mathrm{FeOOH}$ anode are mass balanced at $5.5 \mathrm{Ag}^{-1}$ (Supplementary Fig. 10). As shown in Fig. 6a, series of $\mathrm{CV}$ tests are undertaken in different potential windows in $2 \mathrm{M} \mathrm{KOH}$ to determine the optimal operating potential window of the $\mathrm{NiMoO}_{4} / / \mathrm{FeOOH}$ HSC. Under a potential window of $1.1 \mathrm{~V}$, only one anodic peak is visible, implying that there is no contribution from the cathode and the reactions are irreversible (Fig. 6a). Under a wide potential window of $1.9 \mathrm{~V}$, the aqueous electrolyte begins to decompose. The optimal potential window of the assembled HSC is determined to be $1.7 \mathrm{~V}$. This is in good agreement with the working potential windows of the separate electrodes with respect to the water oxidation and reduction potentials in $2 \mathrm{M} \mathrm{KOH}$ electrolyte (Supplementary Fig. 8). With the increase of voltage potential from 1.1 to $1.7 \mathrm{~V}$ at $11.25 \mathrm{Ag}^{-1}$, the capacitance increases from 87.05 to $230.72 \mathrm{Fg}^{-1}$ (Supplementary Fig. 11a), which is mainly due to the increased redox reactions of the electrodes and it can be confirmed from the $\mathrm{CV}$ integral area (Fig. 6a). Fig. 6b displays typical CV curves of the HSC at different scan rates in a $1.7 \mathrm{~V}$ potential window. The $\mathrm{CV}$ curves have a non-rectangular shape with a couple of broad reversible redox peaks, which indicate the capacitance mainly comes from the redox reactions. The galvanostatic charge/discharge curves of the $\mathrm{NiMoO}_{4} / / \mathrm{FeOOH} \mathrm{HSC}$ at different current densities were tested (Supplementary Fig. 11b). As shown in Fig. 6c, the full HSC delivers a specific capacitance of 273 and $183 \mathrm{Fg}^{-1}$ at a current density of 1.5 and $22.5 \mathrm{Ag}^{-1}$, respectively. The HSC device displays good rate capability with $67 \%$ of the capacitance retained in that current density range. Supplementary Fig. 11c shows the long-term cycling stability of the $\mathrm{NiMoO}_{4} / / \mathrm{FeOOH}$ HSC and it retains $80.8 \%$ of its initial specific capacitance after 10,000 cycles at a current density of $22.5 \mathrm{~A} \mathrm{~g}^{-1}$. The float voltage test, a more demanding test than the conventional charge/ discharge cycling was also used to study the stability of the $\mathrm{NiMoO}_{4} / / \mathrm{FeOOH} \mathrm{HSC}$ in $2 \mathrm{M} \mathrm{KOH}$ electrolyte ${ }^{59,60}$. For a test time of $450 \mathrm{~h}$, the $\mathrm{NiMoO}_{4} / / \mathrm{FeOOH}$ HSC displays exceptional stability with no loss in capacitance (Fig. 6d).

The energy and power density of the HSC were calculated from the galvanostatic discharge curves and plotted in the Ragone plot (Fig. 6e). The HSC displays a maximum gravimetric energy density of $104.3 \mathrm{Wh} \mathrm{kg}^{-1}$ at a power density of $1.27 \mathrm{~kW} \mathrm{~kg}^{-1}$ and an energy density of $31 \mathrm{Wh} \mathrm{kg}^{-1}$ at a maximum power density of $10.94 \mathrm{~kW} \mathrm{~kg}^{-1}$. Volumetric capacitance, volumetric energy and power density are very important parameters for practical applications of supercapacitors ${ }^{51}$. The $\mathrm{NiMoO}_{4} / / \mathrm{FeOOH}$ packaged device displays high volumetric capacitances; even though the active material mass accounts for just $6.5 \mathrm{wt} \%$ of the packaged device, the volumetric capacitances still reach 8.24 and $5.53 \mathrm{~F} \mathrm{~cm}^{-3}$ at 1.5 and $22.5 \mathrm{Ag}^{-1}$, respectively (Fig. 6c). The HSC device also displays a maximum volumetric energy density of $3.15 \mathrm{mWh} \mathrm{cm}^{-3}$ at a power density 

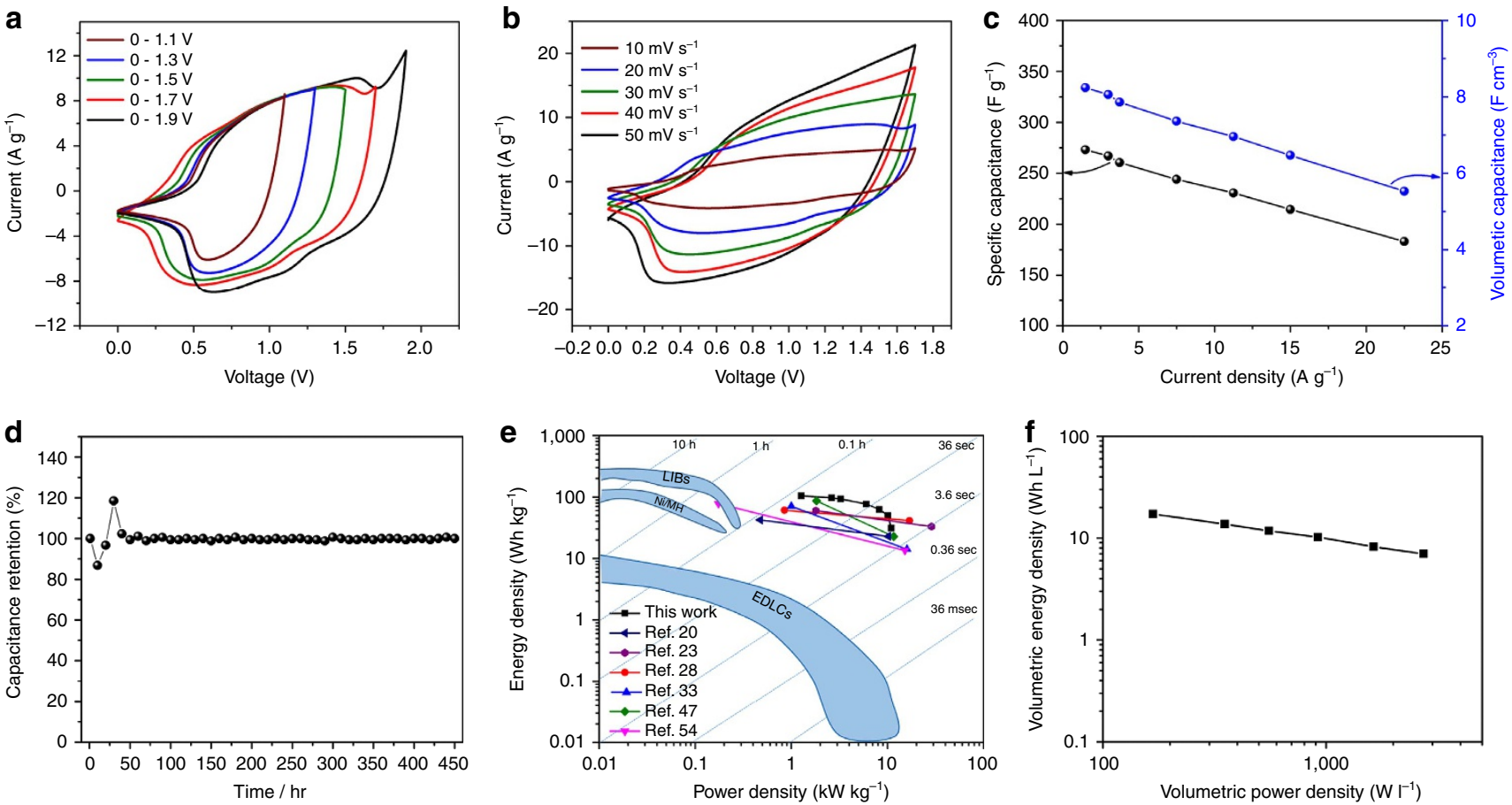

Figure 6 | Electrochemical performance of $\mathrm{NiMoO}_{4} / / \mathbf{F e O O H} \mathbf{H S C}$. (a) CV curves in different potential windows at $20 \mathrm{mVs}^{-1}$. (b) CV curves of the HSC device at various scan rates from 10 to $50 \mathrm{mVs}^{-1}$ in $1.7 \mathrm{~V}$ potential window. (c) The specific gravimetric and volumetric capacitances of the HSC at different current densities. (d) Float voltage stability test of the $\mathrm{NiMoO}_{4} / / \mathrm{FeOOH} \mathrm{HSC}$ for $450 \mathrm{~h}$. (e) Ragone plot of the $\mathrm{NiMoO} 4 / / \mathrm{FeOOH} \mathrm{HSC}$, the energy and power densities of recently reported Ni-metal oxide-based SCs and the conventional storage devices are added for comparison. (f) Volumetric energy and power density of the $\mathrm{NiMoO}_{4} / / \mathrm{FeOOH}$ packaged device. Active material mass accounts for $35 \%$ of the total packaged weight.

of $38.33 \mathrm{~mW} \mathrm{~cm}^{-3}$ and a maximum volumetric power density of $330.62 \mathrm{mw} \mathrm{cm}^{-3}$ at an energy density of $0.68 \mathrm{mWh} \mathrm{cm}^{-3}$ (Supplementary Fig. 12). For practical applications, a $\mathrm{NiMoO}_{4} / /$ $\mathrm{FeOOH}$ packaged device with active materials accounting for $35 \%$ of the total weight is also assembled. It displays a volumetric capacitance of $42.96 \mathrm{~F} \mathrm{~cm}^{-3}$, a maximum energy density of $31.44 \mathrm{Wh} \mathrm{kg}^{-1}$ at a power density of $305 \mathrm{~W} \mathrm{~kg}^{-1}$ and a maximum power density of $4,976 \mathrm{~W} \mathrm{~kg}^{-1}$ at an energy density of $12.72 \mathrm{~W} \mathrm{~kg}^{-1}$ (Supplementary Fig. 13). Last, the packaged device displays maximum volumetric energy and power densities of $17.24 \mathrm{Whl}^{-1}$ and $2,736.08 \mathrm{Wl}^{-1}$, respectively (Fig. 6f).

\section{Discussion}

Using ex situ XRD, XPS, SEM and TEM tests, it has been unambiguously demonstrated that not only the surface but also the bulk of the $\alpha-\mathrm{Fe}_{2} \mathrm{O}_{3}$ nanoparticles can be converted into low-crystalline $\mathrm{FeOOH}$ during the electrochemical activation process, which has been rarely reported. The $\mathrm{FeOOH}$ anode shows characteristic capacitive CV profiles with broad peaks indicating that the stored charge is mainly pseudocapacitive ${ }^{61}$. From the CV curves, the capacitive $\left(k_{1}\right)$ and diffusion $\left(k_{2}\right)$ controlled contributions to the total capacity at a particular voltage can be separated using the equation shown below ${ }^{61-63}$ :

$$
i(V)=k_{1} v+k_{2} v^{\frac{1}{2}}
$$

where $v$ is the sweep rate. Fig. $7 \mathrm{a}-\mathrm{c}$ show a typical separation of capacitive and diffusion currents at scan rates of 1,2 and $5 \mathrm{mV} \mathrm{s}^{-1}$, respectively. As shown in Fig. $7 \mathrm{~d}$, the capacitivecontrolled process contributes $78.9 \%, 84.6 \%$ and $89.6 \%$ of the total charge storage at 1,2 and $5 \mathrm{mV} \mathrm{s}^{-1}$, respectively, suggesting the dominant capacitive charge-storage mechanism in the $\mathrm{FeOOH}$ anode. The dominant capacitive storage endows extraordinary high charge storage kinetics and stable cycling performance ${ }^{53,61-63}$. As a result, even at high mass loadings of $\sim 5.6$ and $9.1 \mathrm{mg} \mathrm{cm}^{-2}$, the $\mathrm{FeOOH}$ anode exhibits excellent comprehensive electrochemical performances, which are essential for the practical application of supercapacitors. Compared to carbon materials, the high specific capacitance of the low-crystalline $\mathrm{FeOOH}$ nanoparticles validates its selection as the anode for fabricating the full $\mathrm{HSC}^{35,36}$. To the best of our knowledge, the low-crystalline $\mathrm{FeOOH}$ nanoparticles display superior electrochemical performances to previously reported iron oxide based nanostructured electrodes (Supplementary Table 3). The FeOOH anode presents the advantages of a wide operating potential window, dominant capacitive charge-storage mechanism and the low-crystalline feature in comparison to several reported iron oxides, which are diffusion-controlled (Supplementary Table 3). A plot of the voltage drops versus current density of both electrodes displays very gentle slopes, which can be ascribed to the low internal resistances and excellent conductivities of the electrodes (Supplementary Fig. 14). The very steep slopes in the Warburg region (Figs $3 \mathrm{f}$ and $5 \mathrm{~d}$ ) indicate high ion mobility and diffusion, which is favourable for rate capability and cycling stability.

Compared with recently reported metal oxide//carbon material full supercapacitors, the $\mathrm{NiMoO}_{4} / / \mathrm{FeOOH} \mathrm{HSC}$ displays superior specific capacitance ${ }^{20-23,26,28}$. Furthermore, the energy density of the assembled HSC exceeds recently reported nickel-based full supercapacitors, such as $\mathrm{Ni}_{2} \mathrm{Co}_{2} \mathrm{~S}_{4} / / \mathrm{G} / \mathrm{CS}$ paper $\left(42.3 \mathrm{Wh} \mathrm{kg}^{-1} \text { at } 476 \mathrm{~W} \mathrm{~kg}^{-1}\right)^{20}, \mathrm{Ni}(\mathrm{OH})_{2} /$ graphene// porous graphene $\left(77.8 \mathrm{Wh} \mathrm{kg}^{-1} \text { at } 174.7 \mathrm{~W} \mathrm{~kg}^{-1}\right)^{54}, \mathrm{FeOOH} / /$ Co-Ni-DH (86.4 $\mathrm{Wh} \mathrm{kg}^{-1}$ at $\left.1.83 \mathrm{~kW} \mathrm{~kg}^{-1}\right)^{47}, \mathrm{NiMoO}_{4} / /$ activated carbon $\left(60.9 \mathrm{Wh} \mathrm{kg}^{-1} \text { at } 850 \mathrm{~W} \mathrm{~kg}^{-1}\right)^{28}$, Ni-Co-S// graphene film $\left(60 \mathrm{Wh} \mathrm{kg}^{-1} \text { at } 1.8 \mathrm{~kW} \mathrm{~kg}^{-1}\right)^{23}$ and $\mathrm{NiMoO}_{4} / /$ $\mathrm{NiMoO}_{4}\left(70.7 \mathrm{Wh} \mathrm{kg}^{-1} \text { at } 1 \mathrm{~kW} \mathrm{~kg}^{-1}\right)^{33}$. The excellent electrochemical performance of the $\mathrm{NiMoO}_{4} / / \mathrm{FeOOH} \mathrm{HSC}$ may be attributed to the following factors: (1) The dominant 

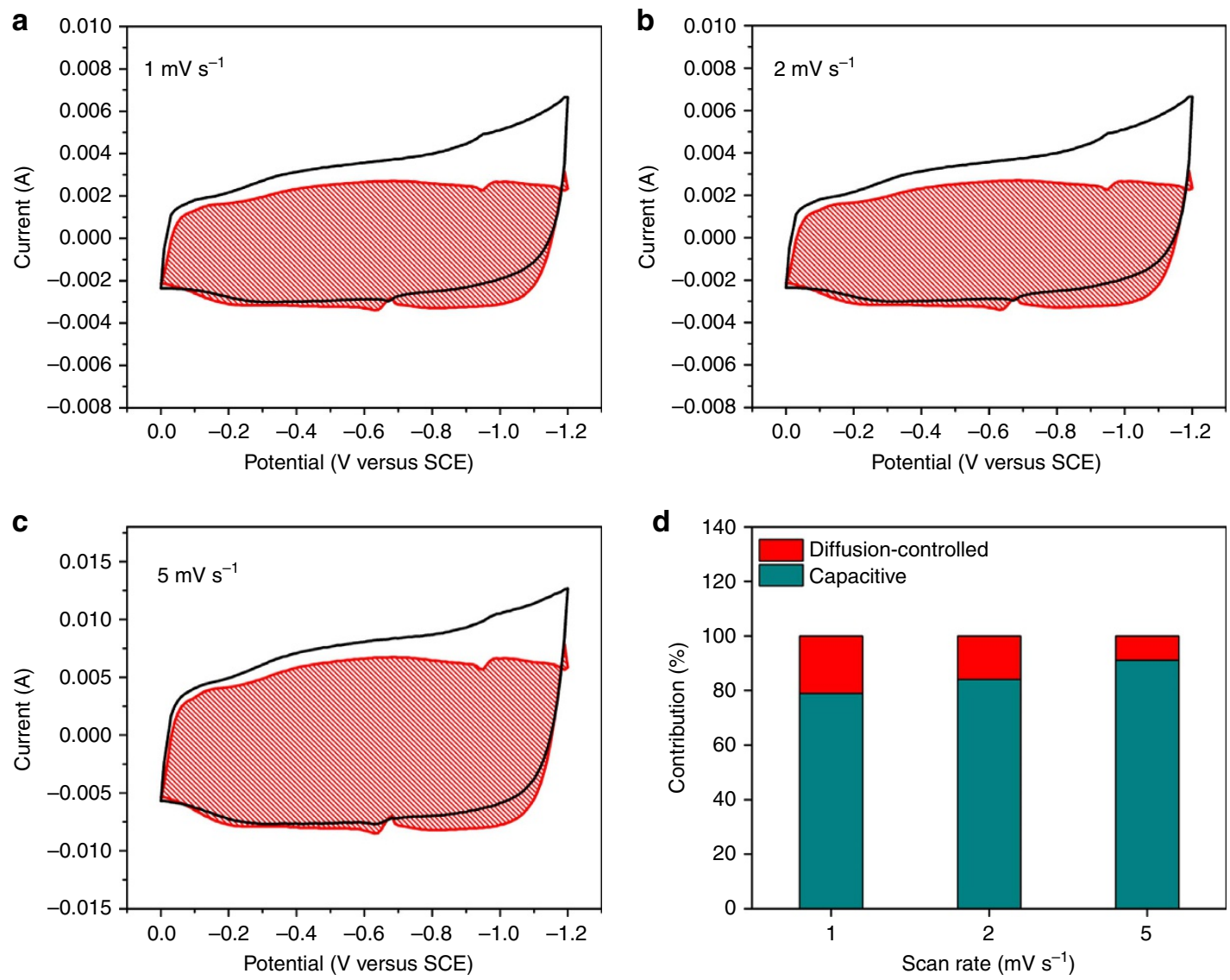

Figure 7 | Capacitive and diffusion-controlled contributions to charge storage. Voltammetric responses for low-crystalline FeOOH nanoparticles at scan rates of (a) $1,(\mathbf{b}) 2$ and (c) $5 \mathrm{mVs}^{-1}$. The capacitive contribution to the total current is shown by the shaded region. (d) The capacitance contribution at different scan rates $\left(1,2\right.$ and $\left.5 \mathrm{mVs}^{-1}\right)$.

capacitive contribution of the low-crystalline $\mathrm{FeOOH}$ nanoparticle anode results in high capacitances in a wide potential window, which translates into the high-energy density of the hybrid device. (2) The $\mathrm{FeOOH}$ nanoparticles present short ion diffusion paths, which are favourable for fast redox reactions, and the low crystalline structure has the self-adaptive strainrelaxation capability during the charge and discharge processes, leading to high stability. (3) The large surface area of the active materials provides more active sites for charge storage. (4) The direct growth of active materials on conductive substrates eliminates the use of a binder, which often inhibits electrode/ electrolyte contact areas and increases the overall resistances of the electrodes. (5) The highly conductive and porous substrates (nickel foam and $\mathrm{CFC}$ ) provide continuous electronic transport and easy accessibility of the electrolytes to the active materials.

In summary, we have successfully developed low-crystalline $\mathrm{FeOOH}$ nanoparticles through a novel strategy involving the hydrothermal growth and the subsequent electrochemical transformation of $\alpha-\mathrm{Fe}_{2} \mathrm{O}_{3}$ nanoparticles. The low-crystalline design of the pseudocapacitive anode with high comprehensive performance largely enhances the energy and power densities of the supercapacitor. Therefore, the well-designed low-crystalline $\mathrm{FeOOH}$ materials could be a very suitable supercapacitor anode for future practical applications due to its low cost, easy preparation, environmental benignity and high comprehensive electrochemical performance at a wide potential window. An assembled $\mathrm{NiMoO}_{4} / / \mathrm{FeOOH} \mathrm{HSC}$ displays a high capacitance of $273 \mathrm{Fg}^{-1}$ at $1.5 \mathrm{Ag}^{-1}$ and a high energy density of $104.3 \mathrm{Wh} \mathrm{kg}^{-1}$ at a power density of $1.27 \mathrm{~kW} \mathrm{~kg}^{-1}$ in an extended potential window $(1.7 \mathrm{~V})$, which largely overcomes the present tremendous challenge of the low-energy density of supercapacitors. Our work also provides a promising design direction for optimizing the electrochemical performance of full supercapacitors using various pseudocapacitive materials with suitable reaction potentials.

\section{Methods}

Synthesis of FeOOH nanoparticles. $\mathrm{Fe}\left(\mathrm{NO}_{3}\right)_{3} \cdot 9 \mathrm{H}_{2} \mathrm{O}(1.212 \mathrm{~g})$ was dissolved in $60 \mathrm{ml}$ distilled water and stirred for $2 \mathrm{~h}$. Afterwards, the resultant clear solution was transferred into a Teflon-lined stainless-steel autoclave containing precleaned CFC The hydrothermal process was carried out at $120^{\circ} \mathrm{C}$ for $24 \mathrm{~h}$. After cooling, the substrate was removed and washed with distilled water. The sample was dried at $70{ }^{\circ} \mathrm{C}$ for $12 \mathrm{~h}$ to obtain the $\alpha-\mathrm{Fe}_{2} \mathrm{O}_{3}$ nanoparticles. The mass of the $\alpha-\mathrm{Fe}_{2} \mathrm{O}_{3}$ nanoparticles on the CFCs can be easily tuned by controlling the synthesis conditions. The $\alpha-\mathrm{Fe}_{2} \mathrm{O}_{3}$ nanoparticles electrodes were electrochemically cycled in a three-electrode cell system by using the as-synthesized materials on the CFC substrate as the working electrode, Pt plate as counter-electrode and SCE as reference electrode in $2 \mathrm{M} \mathrm{KOH}$ electrolyte. The $\alpha-\mathrm{Fe}_{2} \mathrm{O}_{3}$ nanoparticles electrodes were fully transformed into $\mathrm{FeOOH}$ nanoparticles after the tenth cycle in a -1.2 to $0 \mathrm{~V}$ versus SCE potential window.

Synthesis of $\mathrm{NiMoO}_{\mathbf{4}}$ nanowires. The synthesis of $\mathrm{NiMoO}_{4}$ nanowires was achieved by a mild hydrothermal method with postannealing. In a typical synthesis, $\mathrm{NiCl}_{2} \cdot 6 \mathrm{H}_{2} \mathrm{O}(0.725 \mathrm{~g})$ was dissolved in $25 \mathrm{ml} \mathrm{H}_{2} \mathrm{O}$ and stirred for $1 \mathrm{~h}$, followed by drop-wise addition of $25 \mathrm{ml}$ aqueous solution of $\mathrm{Na}_{2} \mathrm{MoO}_{4} \cdot 2 \mathrm{H}_{2} \mathrm{O}$ $(0.740 \mathrm{~g})$ and stirred for another $2 \mathrm{~h}$ (all chemicals were used as received without purification). The resultant solution was transferred into a Teflon-lined stainlesssteel autoclave containing precleaned nickel foams and kept at $120^{\circ} \mathrm{C}$ for $12 \mathrm{~h}$. The as-synthesized precursor was then ultrasonically cleaned at $50 \mathrm{~Hz}$ for $5 \mathrm{~min}$ in distilled water, dried at $70^{\circ} \mathrm{C}$ overnight and finally annealed in argon at $400{ }^{\circ} \mathrm{C}$ for $2 \mathrm{~h}$ at a ramping rate of $5^{\circ} \mathrm{C} \mathrm{min}^{-1}$.

Characterization. The crystallographic characterization of the as-synthesized samples was performed with a Bruker D8 Advance X-ray diffractometer with a 
non-monochromatic $\mathrm{Cu} \mathrm{Ka} \mathrm{X}$-ray source. Field emission SEM images were obtained with a JEOL-7100F microscope. TEM images were collected with JEM-2100F STEM/EDS microscope. The BET surface area was measured using a Tristar II 3,020 instrument at $77 \mathrm{~K}$. Raman spectrum was achieved using a Renishaw RM-1000 laser Raman microscopy system. XPS measurements were performed using a VG Multi Lab 2,000 instrument.

Determination of mass loading. The conductive substrates, nickel foam $\left(2 \times 5 \times 0.04 \mathrm{~cm}^{3}\right)$ and CFCs $\left(2 \times 7 \times 0.035 \mathrm{~cm}^{3}\right)$ were initially weighed before the growth of the active materials. All the samples were washed with distilled water and dried thoroughly at $80^{\circ} \mathrm{C}$ overnight before being weighed with an analytical balance. The mass of the active materials was determined by the mass difference (before and after drying for the anode; before and after calcination for the cathode) divided by the macroscopic area of the conductive substrates. The mass loading of the $\mathrm{NiMoO}_{4}$ and $\mathrm{FeOOH}$ is 1.5 and $1.6 \mathrm{mg} \mathrm{cm}^{-2}$, respectively. The thickness of the samples was measured with a vernier caliper.

Electrochemical measurements. The electrochemical measurements of the individual electrode samples were carried out in a three-electrode cell system with the as-synthesized materials on the conductive substrates as the working electrode, SCE as reference electrode and Pt plate as counter-electrode in a $2 \mathrm{M} \mathrm{KOH}$ electrolyte using an electrochemical workstation (CHI 760D).

The specific capacitances of the electrodes and devices were calculated from the galvanostatic discharge curves at different current densities using the formula below.

$$
C_{\mathrm{s}}=\frac{I \times \Delta t}{m \times \Delta V}
$$

where $C_{\mathrm{s}}\left(\mathrm{Fg}^{-1}\right)$ is the specific capacitance, $I(\mathrm{~A})$ is the discharge current, $\Delta t(\mathrm{~s})$ is the discharge time, $m(\mathrm{~g})$ is the mass of the active material and $\Delta V$ is the operating voltage (obtained from the discharge curves excluding the potential drop). The areal capacitance $\left(C_{\mathrm{A}}, \mathrm{F} \mathrm{cm}^{-2}\right)$ of the electrodes was calculated by replacing the mass loading with the surface area of the electrodes $\left(1 \mathrm{~cm}^{2}\right)$. The volumetric capacitance $\left(C_{\mathrm{v}}, \mathrm{F} \mathrm{cm}^{-3}\right)$ of the $\mathrm{FeOOH}$ nanoparticle anode was calculated by replacing the mass of the active material with the volume of the electrodes (including the volume of the current collectors).

The specific capacities of the $\mathrm{NiMoO}_{4}$ cathode at different current densities were calculated from the galvanostatic discharge curves according to the equation below

$$
C=\frac{I \times \Delta t}{3,600 \times m}
$$

where $C\left(\mathrm{mAh} \mathrm{g}^{-1}\right)$ is the specific capacity, $I(\mathrm{~mA})$ is the discharge current and $m(\mathrm{~g})$ is the mass of the active material.

Electrochemical impedance spectroscopy was performed under a sinusoidal signal over a frequency range from 0.01 to $10^{5} \mathrm{~Hz}$ with a magnitude of $10 \mathrm{mV}$. The internal resistance $\left(R_{\mathrm{s}}\right)$ was also determined from the galvanostatic discharge curves by dividing the voltage drop at the beginning of the discharge $\left(V_{\mathrm{drop}}\right)$ by the applied constant current, $I$ (A) according to the formula below

$$
R_{\mathrm{s}}=\frac{V_{\mathrm{drop}}}{2 I}
$$

Fabrication and evaluation of supercapacitor devices. A supercapacitor was fabricated with $\mathrm{NiMoO}_{4}$ nanowires as cathode and $\mathrm{FeOOH}$ nanoparticles as anode, which were separated with glass fibre filter paper in $2 \mathrm{M} \mathrm{KOH}$ electrolyte. The overall volume of the $\mathrm{NiMoO}_{4} / / \mathrm{FeOOH}$ HSCs includes the active materials, current collectors and separator.

The mass ratio of the positive to negative electrode is obtained by using the equation below

$$
\frac{m_{+}}{m_{-}}=\frac{\left(C_{-} \cdot \Delta V_{-}\right)}{(C)}
$$

where $m_{+}$and $m_{-}$are the mass loading of the $\mathrm{NiMoO}_{4}$ and $\mathrm{FeOOH}$ electrodes, respectively, $\mathrm{C}_{-}$is the specific capacitance of the $\mathrm{FeOOH}$ electrode, $C$ is the specific capacity of the $\mathrm{NiMoO}_{4}$ electrode and $\Delta V_{-}$is the potential window of the FeOOH electrode.

The constant float voltage method was carried out to test the stability of the $\mathrm{NiMoO}_{4} / / \mathrm{FeOOH} \mathrm{HSC}$ using a battery test system (LAND CT2001A). In brief, a constant voltage of $1.7 \mathrm{~V}$ was applied to an assembled supercapacitor device with $\mathrm{NiMoO}_{4}$ and $\mathrm{FeOOH}$ electrodes and $2 \mathrm{M} \mathrm{KOH}$ electrolyte. Three charging/ discharging cycles from 0 to $1.7 \mathrm{~V}$ were performed at a constant current density of $2.5 \mathrm{Ag}^{-1}$ every $10 \mathrm{~h}$ to quantify the corresponding retaining specific capacitance. The total test time was $450 \mathrm{~h}$.
The gravimetric energy density and power density of the as-fabricated HSC were calculated based on the formula shown below

$$
\begin{gathered}
E=\frac{\int I \cdot V(t) \mathrm{d} t}{3.6 m} \\
P=\frac{3600 E}{\Delta t}
\end{gathered}
$$

where $E\left(\mathrm{Wh} \mathrm{kg}^{-1}\right)$ is the energy density, $P\left(\mathrm{~W} \mathrm{~kg}^{-1}\right)$ is the power density, $I(\mathrm{~A})$ is the discharge current, $V(t)$ is the discharge voltage excluding the IR drop, $m(\mathrm{~g})$ is the total mass of the active material (cathode and anode), $\mathrm{d} t$ is the time differential and $\Delta t(\mathrm{~s})$ is the discharge time.

The volumetric capacitance, energy density and power density of the $\mathrm{NiMoO}_{4} / /$ $\mathrm{FeOOH} \mathrm{HSC}$ were calculated based on the formulas below

$$
\begin{gathered}
C_{v}=\frac{I \Delta t}{V \Delta V} \\
E=\frac{\int I \cdot V(t) \mathrm{d} t}{3.6 V} \\
P=\frac{3600 E}{\Delta t}
\end{gathered}
$$

where $C_{v}\left(\mathrm{~F} \mathrm{~cm}^{-3}\right)$ is the volumetric capacitance, $I$ (A) is the discharge current, $\Delta t(\mathrm{~s})$ is the galvanostatic discharge time, $\Delta V$ is the voltage range excluding the potential drop, $V\left(\mathrm{~cm}^{3}\right)$ is the total volume of the supercapacitor device (includes cathode, anode and separator), $E\left(\mathrm{mWh} \mathrm{cm}^{-3}\right)$ is the volumetric energy density of the supercapacitor device, $V(t)$ is the discharge voltage excluding the IR drop and $P\left(\mathrm{~mW} \mathrm{~cm}^{-3}\right)$ is the volumetric power density of the supercapacitor device.

Data availability. All relevant data supporting the findings of this study are available on request from the corresponding author.

\section{References}

1. Arico, A. S., Bruce, P., Scrosati, B., Tarascon, J. M. \& Van Schalkwijk, W. Nanostructured materials for advanced energy conversion and storage devices. Nat. Mater. 4, 366-377 (2005).

2. Liu, C., Li, F., Ma, L. P. \& Cheng, H. M. Advanced materials for energy storage. Adv. Mater. 22, E28-E62 (2010).

3. Hu, C., Song, L., Zhang, Z., Chen, N., Feng, Z. \& Qu, L. Tailored graphene systems for unconventional applications in energy conversion and storage devices. Energy Environ. Sci. 8, 31-54 (2015).

4. Wang, G., Zhang, L. \& Zhang, J. A review of electrode materials for electrochemical supercapacitors. Chem. Soc. Rev. 41, 797-828 (2012).

5. Jiang, J., Li, Y., Liu, J., Huang, X., Yuan, C. \& Lou, X. W. D. Recent advances in metal oxide-based electrode architecture design for electrochemical energy storage. Adv. Mater. 24, 5166-5180 (2012).

6. Simon, P. \& Gogotsi, Y. Materials for electrochemical capacitors. Nat. Mater. 7, 845-854 (2008).

7. Lu, M., Beguin, F. \& Frackowiak, E. Supercapacitors: Materials, Systems and Applications (Wiley, 2013).

8. Zhai, Y., Dou, Y., Zhao, D., Fulvio, P. F., Mayes, R. T. \& Dai, S. Carbon materials for chemical capacitive energy storage. Adv. Mater. 23, 4828-4850 (2011).

9. Wang, X. et al. Three-dimensional strutted graphene grown by substrate-free sugar blowing for high-power-density supercapacitors. Nat. Commun. 4, 2905 (2013).

10. Sun, Y. et al. A bamboo-inspired nanostructure design for flexible, foldable, and twistable energy storage devices. Nano Lett. 15, 3899-3906 (2015).

11. Deng, Y., Xie, Y., Zou, K. \& Ji, X. Review on recent advances in nitrogen-doped carbons: preparations and applications in supercapacitors. J. Mater. Chem. A 4, 1144-1173 (2016).

12. Simon, P., Gogotsi, Y. \& Dunn, B. Where do batteries end and supercapacitors begin? Science 343, 1210-1211 (2014).

13. Choi, N. S. et al. Challenges facing lithium batteries and electrical double-layer capacitors. Angew. Chem. Int. Ed. 51, 9994-10024 (2012).

14. Zhang, L. L. \& Zhao, X. S. Carbon-based materials as supercapacitor electrodes. Chem. Soc. Rev. 38, 2520-2531 (2009).

15. Jiang, H., Lee, P. S. \& Li, C. 3D carbon based nanostructures for advanced supercapacitors. Energy Environ. Sci. 6, 41-53 (2013).

16. Augustyn, V., Simon, P. \& Dunn, B. Pseudocapacitive oxide materials for high-rate electrochemical energy storage. Energy Environ. Sci. 7, 1597-1614 (2014).

17. Lu, Q., Chen, J. G. \& Xiao, J. Q. Nanostructured electrodes for highperformance pseudocapacitors. Angew. Chem. Int. Ed. 52, 1882-1889 (2013).

18. Conway, B. E. Electrochemical Supercapacitors: Scientific Fundamentals snd Technological Applications (Springer Science \& Business Media, 2013). 
19. Yan, J., Wang, Q., Wei, T. \& Fan, Z. Recent advances in design and fabrication of electrochemical supercapacitors with high energy densities. Adv. Energy Mater. 4, 1300816 (2014).

20. Shen, L. et al. Formation of nickel cobalt sulfide ball-in-ball hollow spheres with enhanced electrochemical pseudocapacitive properties. Nat. Commun. 6, 6694 (2015).

21. Qu, L. et al. Interwoven three-dimensional architecture of cobalt oxide nanobrush-graphene@ $\mathrm{Ni}_{x} \mathrm{Co}_{2 x}(\mathrm{OH})_{6 x}$ for high-performance supercapacitors. Nano Lett. 15, 2037-2044 (2015).

22. Zhou, C., Zhang, Y., Li, Y. \& Liu, J. Construction of high-capacitance 3D CoO@polypyrrole nanowire array electrode for aqueous asymmetric supercapacitor. Nano Lett. 13, 2078-2085 (2013).

23. Chen, W., Xia, C. \& Alshareef, H. N. One-step electrodeposited nickel cobalt sulfide nanosheet arrays for high-performance asymmetric supercapacitors. ACS Nano 8, 9531-9541 (2014).

24. Zhu, C. et al. All metal nitrides solid-state asymmetric supercapacitors. $A d v$. Mater. 27, 4566-4571 (2015).

25. Zhang, F. et al. A high-performance supercapacitor-battery hybrid energy storage device based on graphene-enhanced electrode materials with ultrahigh energy density. Energy Environ. Sci. 6, 1623-1632 (2013).

26. Tang, Z., Tang, C. H. \& Gong, H. A high energy density asymmetric supercapacitor from nano-architectured $\mathrm{Ni}(\mathrm{OH})_{2} /$ carbon nanotube electrodes. Adv. Funct. Mater. 22, 1272-1278 (2012).

27. Brousse, T., Bélanger, D. \& Long, J. W. To be or not to be pseudocapacitive? J. Electrochem. Soc. 162, A5185-A5189 (2015).

28. Peng, S., Li, L., Wu, H. B., Madhavi, S. \& Lou, X. W. D. Controlled growth of $\mathrm{NiMoO}_{4}$ nanosheet and nanorod arrays on various conductive substrates as advanced electrodes for asymmetric supercapacitors. Adv. Energy Mater. 5, 1401172 (2015).

29. Long, C. et al. Nitrogen-doped carbon networks for high energy density supercapacitors derived from polyaniline coated bacterial cellulose. Adv. Funct. Mater. 24, 3953-3961 (2014).

30. Li, H. B. et al. Amorphous nickel hydroxide nanospheres with ultrahigh capacitance and energy density as electrochemical pseudocapacitor materials. Nat. Commun. 4, 1894 (2013).

31. Jiang, W. et al. Ternary hybrids of amorphous nickel hydroxide-carbon nanotube-conducting polymer for supercapacitors with high energy density, excellent rate capability, and long cycle life. Adv. Funct. Mater. 25, 1063-1073 (2015).

32. Xia, X. et al. A new type of porous graphite foams and their integrated composites with oxide/polymer core/shell nanowires for supercapacitors: structural design, fabrication, and full supercapacitor demonstrations. Nano Lett. 14, 1651-1658 (2014).

33. Guo, D., Luo, Y., Yu, X., Li, Q. \& Wang, T. High performance $\mathrm{NiMoO}_{4}$ nanowires supported on carbon cloth as advanced electrodes for symmetric supercapacitors. Nano Energy 8, 174-182 (2014).

34. Cai, D. et al. Comparison of the electrochemical performance of $\mathrm{NiMoO}_{4}$ nanorods and hierarchical nanospheres for supercapacitor applications. ACS Appl. Mater. Interfaces 5, 12905-12910 (2013).

35. Yu, M. et al. Recent progress in the development of anodes for asymmetric supercapacitors. J. Mater. Chem. A 4, 4634-4658 (2016).

36. Zheng, J. P. The limitations of energy density of battery/double-layer capacitor asymmetric cells. J. Electrochem. Soc. 150, A484-A492 (2003).

37. Pell, W. G. \& Conway, B. E. Perculiarities and requirements of asymmetric capacitor devices based on combination of capacitor and battery-type electrodes. J. Power Sources 136, 334-345 (2004).

38. Yang, P. et al. Low-cost high-performance solid-state asymmetric supercapacitors based on $\mathrm{MnO}_{2}$ nanowires and $\mathrm{Fe}_{2} \mathrm{O}_{3}$ nanotubes. Nano Lett. 14, 731-736 (2014).

39. Chen, L. F. et al. Metal-like fluorine-doped $\beta$-FeOOH nanorods grown on carbon cloth for scalable high-performance supercapacitors. Nano Energy 11, 119-128 (2015)

40. Wang, H. et al. One-step preparation of single-crystalline $\mathrm{Fe}_{2} \mathrm{O}_{3}$ particles/graphene composite hydrogels as high performance anode materials for supercapacitors. Nano Energy 7, 86-96 (2014).

41. Qu, Q., Yang, S. \& Feng, X. 2D sandwich-like sheets of iron oxide grown on graphene as high energy anode material for supercapacitors. Adv. Mater. 23, 5574-5580 (2011)

42. Lu, X. et al. Oxygen-deficient hematite nanorods as high-performance and novel negative electrodes for flexible asymmetric supercapacitors. Adv. Mater. 26, 3148-3155 (2014).

43. Guan, C. et al. Iron oxide-decorated carbon for supercapacitor anodes with ultrahigh energy density and outstanding cycling stability. ACS Nano 9, 5198-5207 (2015).

44. Xia, H. et al. Facile synthesis of hematite quantum-dot/functionalized graphene-sheet composites as advanced anode materials for asymmetric supercapacitors. Adv. Funct. Mater. 25, 627-635 (2015).
45. Li, H., Gao, Y., Wang, C. \& Yang, G. A simple electrochemical route to access amorphous mixed-metal hydroxides for supercapacitor electrode materials. Adv. Energy Mater. 5, 1401767 (2015).

46. Liu, J., Zheng, M., Shi, X., Zeng, H. \& Xia, H. Amorphous FeOOH quantum dots assembled mesoporous film anchored on graphene nanosheets with superior electrochemical performance for supercapacitors. Adv. Funct. Mater. 26, 919-930 (2016).

47. Chen, J., Xu, J., Zhou, S., Zhao, N. \& Wong, C. P. Amorphous nanostructured $\mathrm{FeOOH}$ and $\mathrm{Co}-\mathrm{Ni}$ double hydroxides for high-performance aqueous asymmetric supercapacitors. Nano Energy 21, 145-153 (2016).

48. Reddy, M. V. et al. $\alpha-\mathrm{Fe}_{2} \mathrm{O}_{3}$ nanoflakes as an anode material for Li-ion batteries Adv. Funct. Mater. 17, 2792-2799 (2007).

49. Jeong, J. M. et al. Hierarchical hollow spheres of $\mathrm{Fe}_{2} \mathrm{O}_{3} @$ polyaniline for lithium ion battery anodes. Adv. Mater. 25, 6250-6255 (2013).

50. Chen, Y. C. et al. Novel iron oxyhydroxide lepidocrocite nanosheet as ultrahigh power density anode material for asymmetric supercapacitors. Small 10, 3803-3810 (2014).

51. Gogotsi, Y \& Simon, P. True performance metrics in electrochemical energy storage. Science 334, 917-918 (2011).

52. Zhu, Y. et al. Carbon-based supercapacitors produced by activation of graphene. Science 332, 1537-1541 (2011).

53. Zhao, K. et al. Graphene oxide wrapped amorphous copper vanadium oxide with enhanced capacitive behavior for high-rate and long-life lithium-ionbattery anodes. Adv. Sci. 2, 1500154 (2015).

54. Yan, J. et al. Advanced asymmetric supercapacitors based on $\mathrm{Ni}(\mathrm{OH})_{2}$ /graphene and porous graphene electrodes with high energy density. Adv. Funct. Mater. 22, 2632-2641 (2012).

55. Yin, Z. et al. Hierarchical nanosheet-based $\mathrm{NiMoO}_{4}$ nanotubes: synthesis and high supercapacitor performance. J. Mater. Chem. A 3, 739-745 (2015).

56. Hong, W. et al. Rational construction of three dimensional hybrid $\mathrm{Co}_{3} \mathrm{O}_{4} @ \mathrm{NiMoO}_{4}$ nanosheets array for energy storage application. J. Power Sources 270, 516-525 (2014).

57. Wang, B., Li, S., Wu, X., Liu, J. \& Tian, W. Hierarchical $\mathrm{NiMoO}_{4}$ nanowire arrays supported on macroporous graphene foam as binder-free 3D anodes for high-performance lithium storage. Phys. Chem. Chem. Phys. 18, 908-915 (2016).

58. Yu, Z., Tetard, L., Zhai, L. \& Thomas, J. Supercapacitor electrode materials: nanostructures from 0 to 3 dimensions. Energy Environ. Sci. 8, 702-730 (2015)

59. Weingarth, D., Foelske-Schmitz, A. \& Kötz, R. Cycle versus voltage holdwhich is the better stability test for electrochemical double layer capacitors? J. Power Sources 225, 84-88 (2013).

60. Yang, X., Cheng, C., Wang, Y., Qiu, L. \& Li, D. Liquid-mediated dense integration of graphene materials for compact capacitive energy storage. Science 341, 534-537 (2013).

61. Brezesinski, T., Wang, J., Tolbert, S. H. \& Dunn, B. Ordered mesoporous $\alpha-\mathrm{MoO}_{3}$ with iso-oriented nanocrystalline walls for thin-film pseudocapacitors. Nat. Mater. 9, 146-151 (2010).

62. Bard, A. J. \& Faulkner, L. R Electrochemical Methods: Fundamentals and Applications (Wiley, 1980).

63. Brezesinski, T., Wang, J., Polleux, J., Dunn, B. \& Tolbert, S. H. Templated nanocrystal-based porous $\mathrm{TiO}_{2}$ films for next-generation electrochemical capacitors. J. Am. Chem. Soc. 131, 1802-1809 (2009).

\section{Acknowledgements}

This work was supported by the National Key Research and Development Program of China (2016YFA0202603), the National Basic Research Program of China (2013CB934103), the Programme of Introducing Talents of Discipline to Universities (B17034), the National Natural Science Foundation of China (51521001, 51502226 21673171), the National Natural Science Fund for Distinguished Young Scholars (51425204), the Fundamental Research Funds for the Central Universities (WUT: 2015-YB-002, 2016III001, 2016III002) and the Students Innovation and Entrepreneurship Training Program (20151049701006). L.B.Q. would like to acknowledge the support from The Monash Centre for Atomically Thin Materials.

\section{Author contributions}

K.A.O. and L.B.Q. contributed equally to this work. L.Q.M., K.A.O. and L.B.Q. conceived and designed the experiments. K.A.O., L.B.Q. and C.Y. carried out most of the experiments and analyzed the data. K.N.Z. carried out the Reitveld XRD characterization. Z.Y.W. and K.A.O. carried out the XPS characterization. K.A.O., L.B.Q., L.Z. and L.Q.M cowrote and revised the paper. All authors commented on and discussed the results.

\section{Additional information}

Supplementary Information accompanies this paper at http://www.nature.com/ naturecommunications

Competing financial interests: The authors declare no competing financial interests. 
Reprints and permission information is available online at http://npg.nature.com/ reprintsandpermissions/

How to cite this article: Owusu, K. A. et al. Low-crystalline iron oxide hydroxide nanoparticle anode for high performance supercapacitors. Nat. Commun. 8, 14264 doi: 10.1038/ncomms14264 (2017).

Publisher's note: Springer Nature remains neutral with regard to jurisdictional claims in published maps and institutional affiliations. (c) (i) This work is licensed under a Creative Commons Attribution 4.0 International License. The images or other third party material in this article are included in the article's Creative Commons license, unless indicated otherwise in the credit line; if the material is not included under the Creative Commons license, users will need to obtain permission from the license holder to reproduce the material. To view a copy of this license, visit http://creativecommons.org/licenses/by/4.0/

(C) The Author(s) 2017 